\title{
Converter with four quadrant switches for EDM applications
}

\author{
J. Baizán, A. Navarro-Crespín, R. Casanueva, F. J. Azcondo, C. Brañas, F. J. Díaz \\ Dept. of Electronics Technology, Systems and Automation Engineering \\ University of Cantabria \\ Santander, Spain \\ casanuer@unican.es
}

\begin{abstract}
This paper presents a high-frequency rectifier stage using four quadrant switches as synchronous rectifiers for an electrical discharge machining (EDM) power supply. The EDM impulse generator is a series-parallel resonant inverter operating in current-mode. The device specifications and drive requirements of the converter are studied with the objective of generating unipolar and bipolar current waveforms suitable for different types of EDM operations.
\end{abstract}

Index Terms-electrical discharge machining; EDM; EDM power supply; four-quadrant switch; synchronous rectification; resonant power conversion.

\section{INTRODUCTION}

Electrical discharge machining (EDM) is a nonconventional machining process. Material is removed from the workpiece by a series of repeated electrical discharges between the electrode (tool) and the workpiece, both in presence of a dielectric fluid and separated a distance called the gap [1].

By means of a pulsed power supply, short-duration discharges are generated across the gap. The high temperature reached by each discharge produces a micro melt that removes material which is swept away by the dielectric fluid, gradually achieving the mirror image of the electrode shape in the workpiece. EDM does not make direct contact between the electrode and the work piece, thus it can eliminate mechanical stresses, chatter and vibration problems during machining [2]. EDM is a slow machining process compared to milling and turning processes, but is not affected by material hardness and strength. So it can be used in any electrically conductive material, with special interest in very hard electrically conductive materials which are difficult to machine by conventional methods [3].

The adjustable parameters of the power supply are the pulse duration, the pause duration and the peak current. Additionally, the polarity of the electrode can be set to be positive or negative.

The electrical parameters are established depending on the materials of the workpiece and the electrode, and also on the specific machining operation, owing to the fact that the process parameters affect the main performance measures: metal removal rate (MRR), electrode wear (EW) and surface finish (SF).

When water is used as a dielectric fluid, bipolar pulse generators are required to suppress or minimize the electrolysis effect on the workpiece, which produces oxidation and corrosion. As a result, better surface integrity is obtained compared with the use of dc unipolar pulse generators [4]-[6].

The aim of this work is to develop a synchronous converter employed as an output stage in an EDM power supply, whose previous stage is a series-parallel resonant converter designed as a current source, allowing the modification of the frequency (freqAC in Fig. 1), the duty cycle ( $d$ in Fig. 1) and the polarity of the discharge current. The objective is to improve the SF of the machined pieces and MRR of the process. This proposal results in a small size and light weight equipment, so it can be used for portable on-site machining.

\section{PROPOSED OUTPUT WAVEFORMS}

In this work a topology accomplishing the following conditions is sought:

1. It must be capable of supplying the load with different $\mathrm{AC}$ frequencies.

2. It should include duty cycle adjustment capability.

3. It should rectify high frequency ac input current.

These conditions are illustrated in Fig.1.

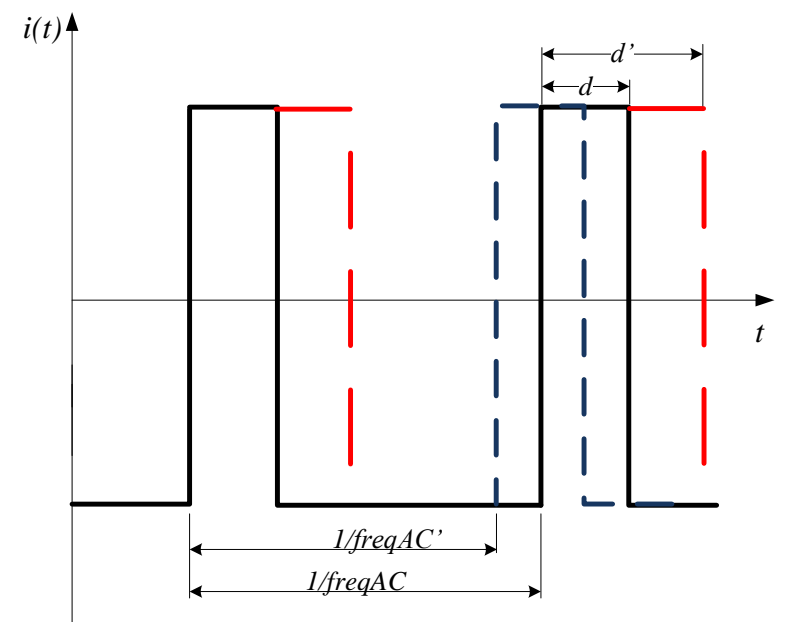

Fig. 1. Proposed current envelope waveform.

The aim of the first two conditions is to enable a suitable bipolar current waveform to be established through the gap, for a specific machining operation. The high frequency in the third condition is the resonant inverter switching frequency. 


\section{BIPOLAR OUTPUT RECTIFIER}

The proposed configuration is a synchronous rectifier (SR) with four quadrant switches as SRs. The utilization of four quadrant switches (4QSWs) to perform the synchronous output conversion [7] is a new proposal in EDM power supplies, which is the reason why this work opens up the many possibilities that the synchronous output conversion provides in this field. This stage is traditionally used in AC to DC power conversion applications. The substitution of the SRs by four quadrant switches (4QSWs) allows the converter to supply loads with $\mathrm{AC}$ of different frequencies and duty cycles, including the DC case, with suitable control.

Fig. 2 shows some possible theoretical current waveforms to be applied in an EDM process.

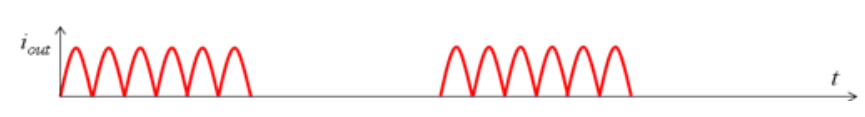

(a)

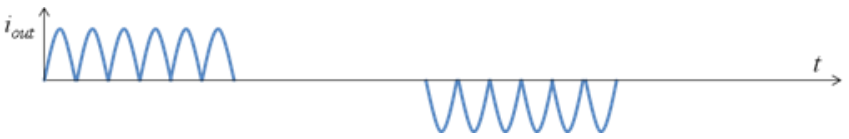

(b)

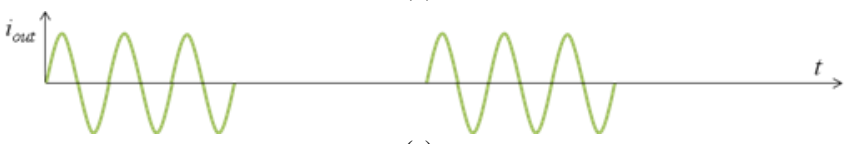

(c)

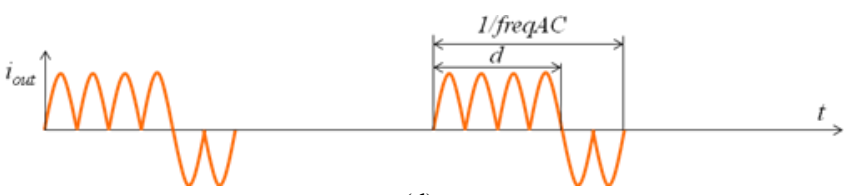

(d)

Fig. 2. Conceptual diagrams of the proposed output current waveforms: (a) positive unipolar, (b) bipolar, (c) bipolar at the inverter frequency and (d) bipolar with adjustable freqAC frequency and $d$ duty cycle.

In this way, the proposed system supplies the gap with unipolar or bipolar current, the second being more convenient for the metal part and for the machining operation conditions. Furthermore, if finishing operations are being performed, which require low-energy discharges, the operating frequency (freqAC) can be the inverter switching frequency (higher than $100 \mathrm{kHz})$.

\section{A. Operation principle}

Fig. 3 shows the proposed solution for the output stage and the voltage waveforms in the primary and secondary side of the transformer and the output voltage.

As it is shown in Fig. 3, to obtain a positive output voltage waveform, 4QSW1 should conduct when the voltage $v_{\text {secl }}$ is positive and 4QSW2 should conduct when $v_{\sec 2}$ is positive.

Conversely, if 4QSW1 conducts when the voltage $v_{\text {secl }}$ is negative and 4QSW2 conducts when $v_{\sec 2}$ is negative, then the resulting output voltage is negative.
By establishing a suitable switching sequence for the 4QSWs, the polarity of the output waveform can be inverted and the frequency of the supplied bipolar current waveform can be selected ideally from dc up to the resonant inverter switching frequency.
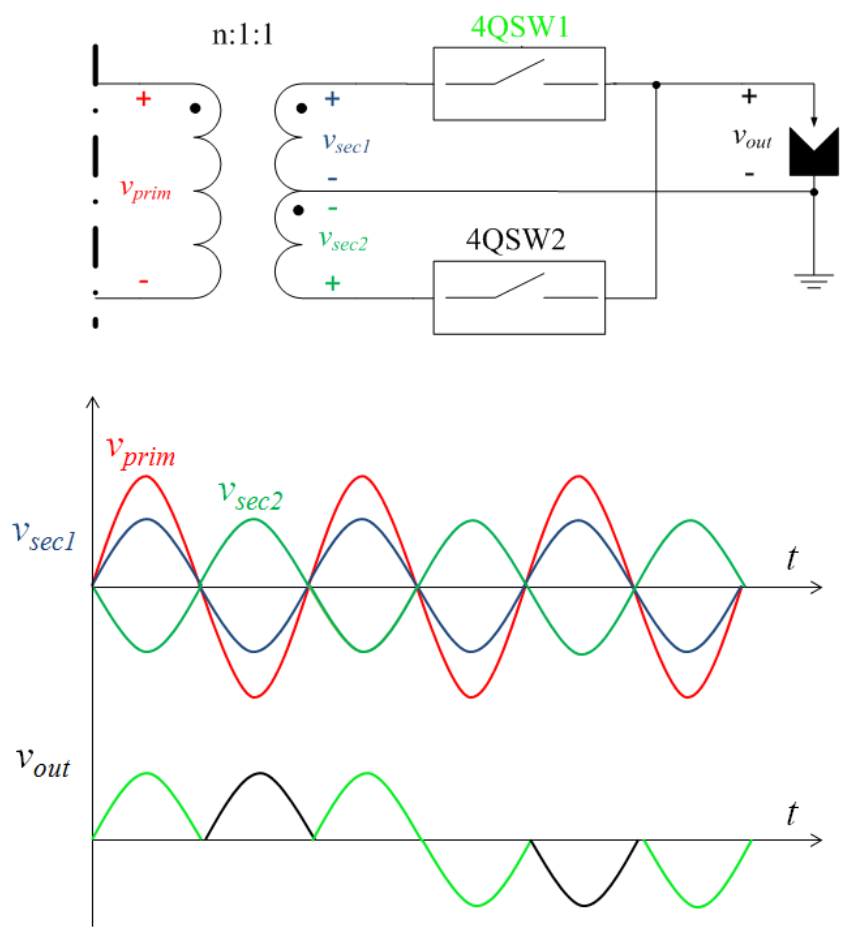

Fig. 3. Output stage and main waveforms. The color of each semiperiod of the output waveform corresponds to the on-state switch.

\section{POWER SUPPLY FOR EDM APPLICATIONS}

\section{A. System overview}

The system is a power supply designed as a current source [8], with a converter with 4 QSWs as an output stage. Fig. 4 shows the circuit diagram of the proposed power supply.

High power density and efficiency motivate the use of resonant converters. Here, the open loop response to large load variations is an additional characteristic behind the selection of $L C_{s} C_{p}$ resonant inverter for this application. In comparison with the $L L C$ resonant tank, the $L C_{s} C_{p}$ keeps the zero-voltage switching mode at any load value, when operating as a current source at the series-parallel resonant frequency. The $L C_{p}$ tank also has the soft-switching and current source characteristics, but the additional $C_{s}$ of the $L C_{s} C_{p}$ inverter cancels out any dc component of the inverter output voltage. Penalizing the power density, the transformer connected at the inverter output is designed to have larger magnetizing impedance than the parallel capacitor, $C_{p}$, impedance, while the transformer leakage inductance is lumped in the series inductance, $L$, of the resonant tank. The series-parallel resonant inverter can reach the required voltage to achieve the dielectric breakdown and to maintain the discharge voltage. The inverter switches at a high frequency, slightly above the resonant frequency. In this way, the resonant current lags voltage, so this topology achieves 


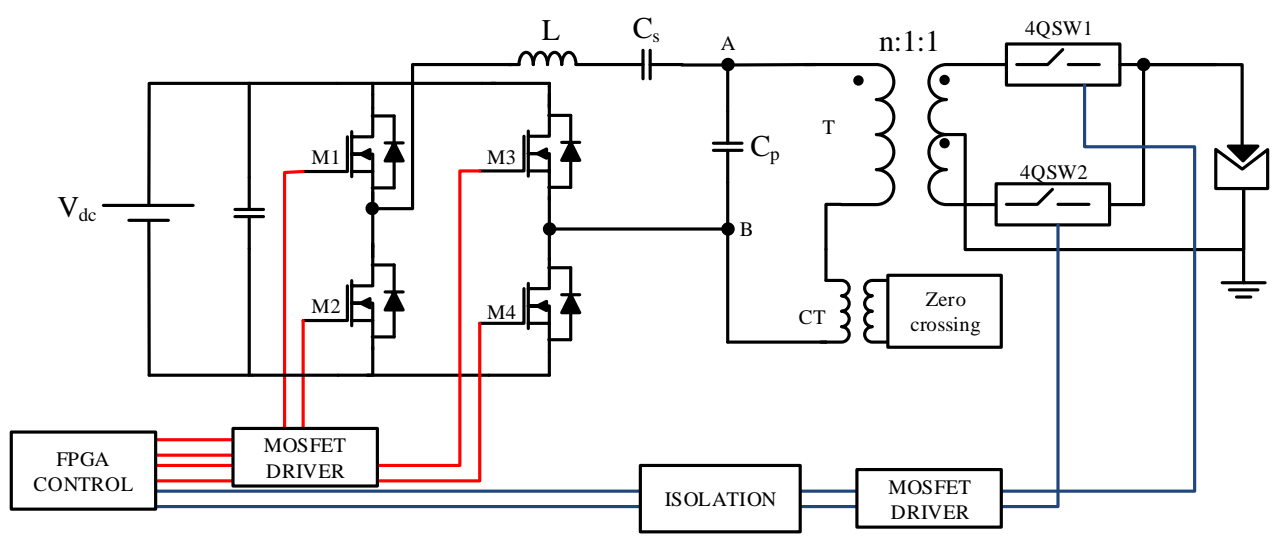

Fig. 4. Circuit diagram of the power supply.

zero-voltage switching and thus minimal switching losses. The resonant inverter is designed to provide a constant current for all the gap conditions, in this way, the system is inherently protected under short circuit conditions. To limit the open circuit voltage an over-voltage protection circuit is included. A high-frequency center-tapped transformer reduces the resonant inverter output voltage to supply the gap with the required voltage. The control functions are performed by a field programmable gate array (FPGA). This device generates the switching signals for the resonant inverter stage and the 4 QSWs.

\section{B. Switch selection}

The switches of the output stage are required to: 1) have the capability of bidirectional current conduction and voltageblocking capability and 2) have high switching frequency performance. They are obtained by the combination of available switches [9].

4QSWs are employed in bi-directional buck-boost converters, cyclo-converters [10] and rectifiers such as the Vienna rectifier II [11]. The switch selection depends on the static and dynamic specifications.

Power MOSFETs can withstand high over current turn-on transients without undergoing destructive failure. MOSFETs have limited power conversion capacity. However, for lowpower and high-frequency applications like this one, they are suitable because of their high switching rate and negligible losses. In this application, MOSFETs are found to be the most appropriate switch choice.

The 4QSWs are constructed using the common-source back-to-back MOSFETs configuration shown in Fig. 5 [12].

The common source configuration is chosen for simplicity's sake, both MOSFETs can be controlled with one gate driver and this requires fewer isolated power supplies. Power MOSFETs include a body diode [13] which produces more losses when is directly biased than the conduction through the channel. The back-to-back configuration eliminates the current flow through the diodes, reducing the conduction losses that eventually could damage the devices.

Since the resonant converter operates in current source mode, the elimination of the dead-time or even the overlap of the converter drive signal can reduce the switching losses and noise while operation is safe under short-circuit condition.

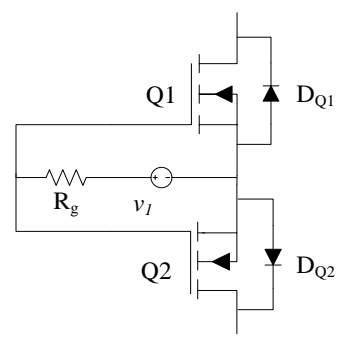

Fig. 5. Two back-to-back MOSFET: common-source configuration.

The snubber circuit provides a current path during the switching process and protects the MOSFET switches against high overvoltage during the switching transients [12]-[14].

The snubber network is designed for damping the oscillations (ringing) produced by the LC circuit by the parasitic inductance of transformer $\left(\mathrm{L}_{\sigma}\right)$, the layout $\left(\mathrm{L}_{P C B}\right)$, the package inductance of the MOSFETs $\left(\mathrm{L}_{\text {drain }}\right.$ and $\left.\mathrm{L}_{\text {source }}\right)$, and the MOSFETs $\left(C_{\text {oss }}\right)$ [15], [16].

$$
f_{o}=\frac{1}{2 \pi \sqrt{L_{\text {total }} C_{o s s}}}
$$

where $L_{\text {total }}$ is the addition of: $\mathrm{L}_{\sigma}, \mathrm{L}_{P C B}, \mathrm{~L}_{\text {drain }}$ and $\mathrm{L}_{\text {source }}$; and $C_{o s s}$ is the output capacitance of the MOSFET.

There are different dissipative and non-dissipative configurations to build the snubber. In this case, an $R C$, i.e. dissipative, snubber has been chosen for simplicity reasons. The switches are implemented with the series connection of two MOSFETs. Among the possible arrangements shown in Fig. 6, the selected allocation for the snubber circuit, Fig. 6 (a), minimizes the parasitic inductance, and therefore results in lower power loss and better oscillation damping. 


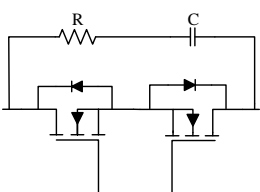

(a)

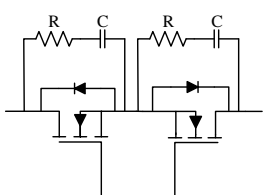

(b)

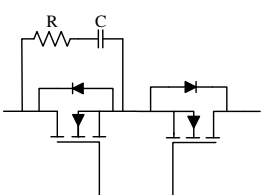

(c)
Fig. 6. Evaluated $R C$ snubber circuit.

\section{Control algorithm}

Depending on the load imposed by the process, i.e. taking into account the workpiece material and the machining conditions, the current on the secondary side of the transformer has a delay with respect to the input voltage of the resonant circuit.

Fig. 7 shows the block diagram of the circuit that controls the 4QSWs.

The control algorithm synchronizes the 4QSWs with the current on the secondary side of the transformer [17]. The zero-crossing $(Z C)$ of the current on the secondary side of the transformer is detected. This signal is obtained by means of a series current transformer located in the primary side of the transformer, where the current has the same shape and phase and a smaller value than on the secondary side.

The Count signal is a counter output which represents the phase difference between the $Z C$ of the secondary current and the falling edge of $M 1$, which corresponds to the input voltage of the resonant circuit.

This phase difference is collected and modified with the constant $K$, which accounts for the propagation delay of the components used to drive the 4QSWs (opto-couplers, comparator, drivers, etc). The resulting signal, $\beta$, represents the phase-lag that the algorithm has to introduce to generate the internal signals $4 Q 1$ int and $4 Q 2$ int, which are applied to the next switching period synchronized with the transformer's secondary current and voltage $\left(v_{\text {sec }}\right)$ when the converter acts as a SR.

The proposed control has a predictive nature because the calculated phase is applied in the next switching cycle (based on the assumption that the phase lag required for the next switching period will be similar to the current period).

The control parameters of the output current for the converter are: freqAC and the duty cycle, $d$ (see Fig. 1). The signal freqAC is used to select the frequency of the $\mathrm{AC}$ component of the output current and the duty cycle denotes the pulse width of the positive current as shown in Fig. 1. The period of freqAC is an integer number of times the switching period of the resonant inverter. Fig. 8 shows the construction of a bipolar waveform at a frequency equal to half of the inverter switching frequency. The signal freq indicates the polarity, the frequency and the duty cycle of the output current. This signal indicates the trigger sequence in the $4 Q S W s$. For example, with freq at zero $4 Q S W 1$ is triggered first and $4 Q W S 2$ later and this order will be maintained as long as freq remains at zero. When freq is active the sequence is the opposite.

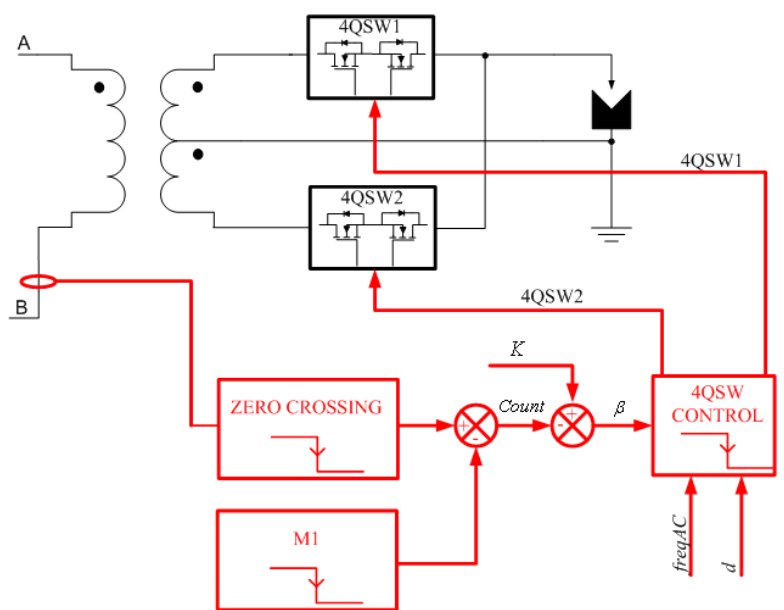

Fig. 7. 4QSWs control circuit block diagram.

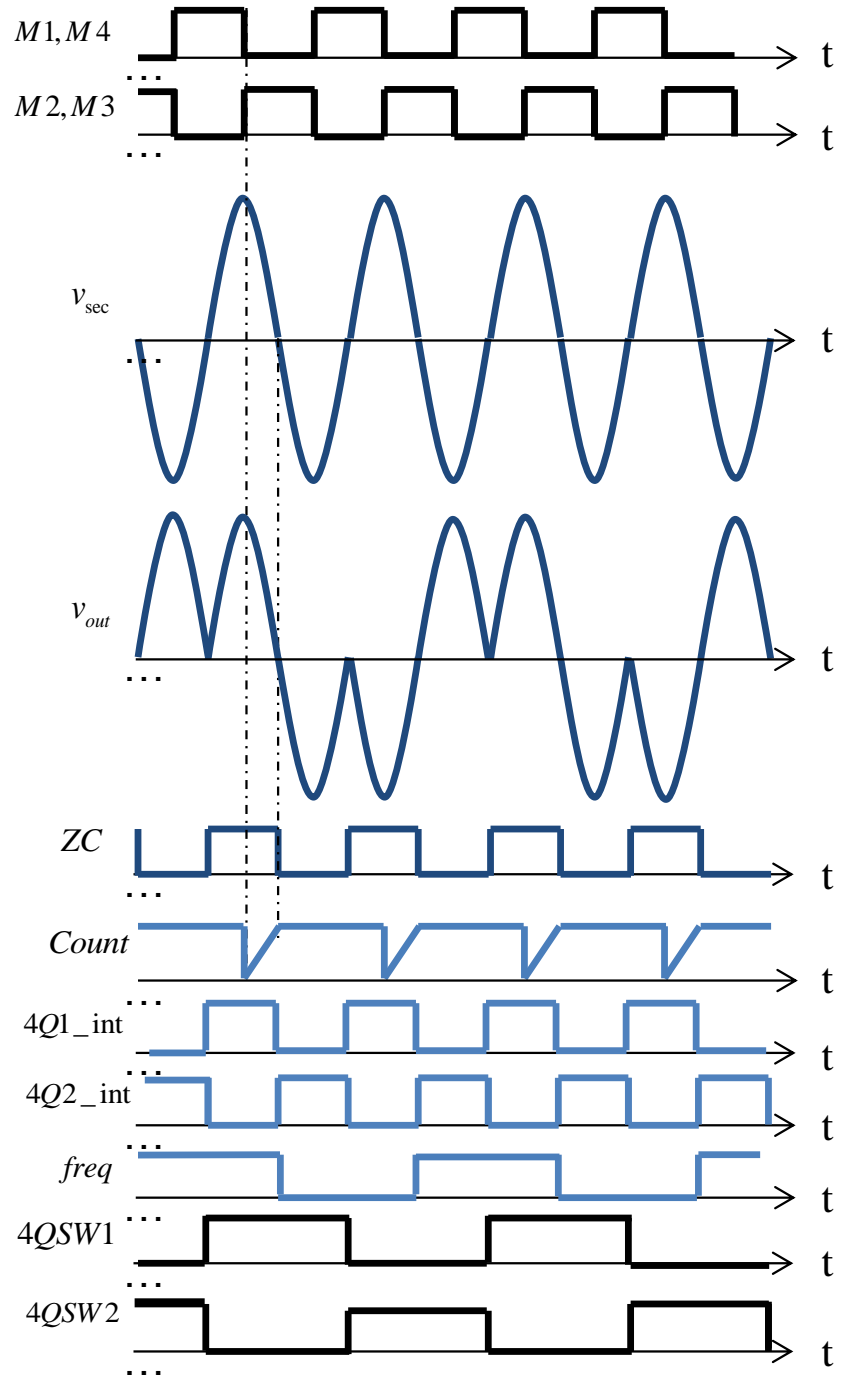

Fig. 8. Main waveforms of $4 \mathrm{QSW}$ control: resonant inverter drive signals $(M 1, M 2, M 3, M 4)$, transformer output voltage $\left(v_{s e c}\right)$, zero-crossing detection signal $(Z C)$, phase delay measurement signal (Count),internal synchronized signals with the secondary current and voltage (4Q1_int, 4Q2_int), polarity selection signal freq and 4QSWs drive signals (4QSW1, 4QSW2). 


\section{EXPERIMENTAL RESULTS}

A first verification of the proposed circuit has been carried out by means of fixed load resistances which emulate the different gap conditions in steady state. The resonant circuit components are $\mathrm{L}=131 \mu \mathrm{H}, \mathrm{C}_{\mathrm{s}}=25 \mathrm{nF}, \mathrm{C}_{\mathrm{p}}=6.2 \mathrm{nF}$, the switching frequency is $208 \mathrm{kHz}$. The inverter MOSFET transistors are IRFP350 $\left(V_{D S S}=400 \mathrm{~V}, I_{D}=16 \mathrm{~A}, R_{D S(o n)}=\right.$ $0.30 \Omega)$. The 4QSWs are STB28NM50N $\left(V_{D S S}=500 \mathrm{~V}, I_{D}=\right.$ $21 \mathrm{~A}, R_{D S}(o n), \max =0.158 \Omega$ ). The nominal load resistance is $2.14 \Omega$. The measured parameters of the power transformer are: magnetizing inductance, $\mathrm{L}_{\mathrm{m}}=990 \mu \mathrm{H}$, leakage inductance, $\mathrm{L}_{\sigma}=5.58 \mu \mathrm{H}$. The transformation ratio is $6.9: 1: 1$.

For the lab experiments a dc voltage supply has been used as the input dc source, connection to the utility requires a power factor correction stage to limit the line harmonics.

Fig. 9 shows the voltage drop across the 4QSW terminals (drains) and the output current working at $69.3 \mathrm{kHz}$ and a duty cycle of $50 \%$.

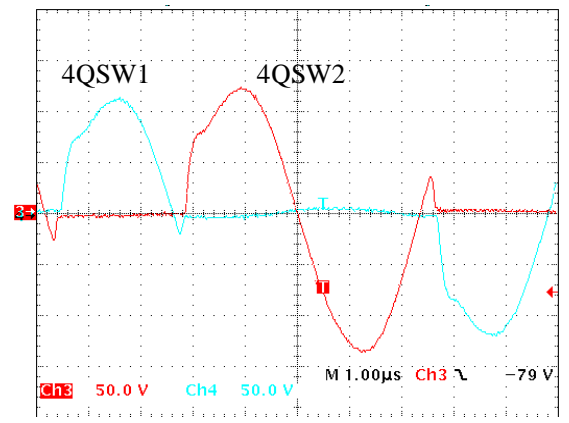

Fig. 9. Voltage waveform across drains of the 4QSW1 (blue), voltage waveform between drains of the 4QSW2 (red). FreqAC $=69.3 \mathrm{kHz}, d=$ $50 \%$. Ch3 and Ch4 scale: $50 \mathrm{~V} /$ div, time scale: $1 \mu \mathrm{s} / \mathrm{div}$.

Fig. 10 shows the output current waveforms at a frequency freqAC $=34.7 \mathrm{kHz}$ and different duty cycles, in Fig. 10 (a), $d$ $=25 \%$ and in Fig. 10 (b) $d=50 \%$. The high frequency current ripple is lower than the theoretically predicted one due to the filtering action of the wires connecting the power stage to the load and the parasitic inductance and capacitance of the load.

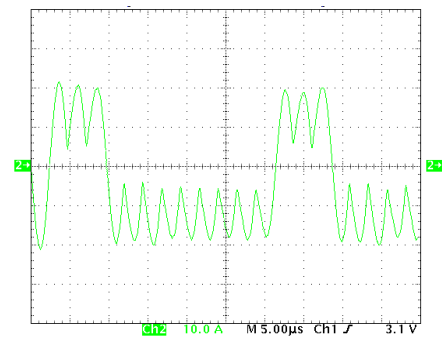

(a)

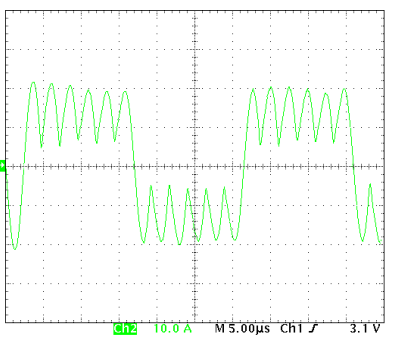

(b)
Fig. 10. Output current waveform. Bipolar operating mode at freqAC $=34.7$ $\mathrm{kHz}$, a) $d=25 \%$ and b) $d=50 \%$. Ch2 scale: $10 \mathrm{~V} / \mathrm{div}$, time scale: $5 \mu \mathrm{s} / \mathrm{div}$.

Fig. 11 shows the output voltage and current waveforms with freqAC $=26 \mathrm{kHz}, d=25 \%$ for a machining frequency of $3.5 \mathrm{kHz}$ with a duty cycle of $50 \%$. During the initial interval of the pulse time, a bipolar pulse at the switching frequency
$(208 \mathrm{kHz})$ is provided in order to allow the algorithm to perform a first calculation of the delay. The rms value of the output voltage and current during the pulse time is $\sim 24 \mathrm{~V}$ and $\sim 12$ A, respectively.

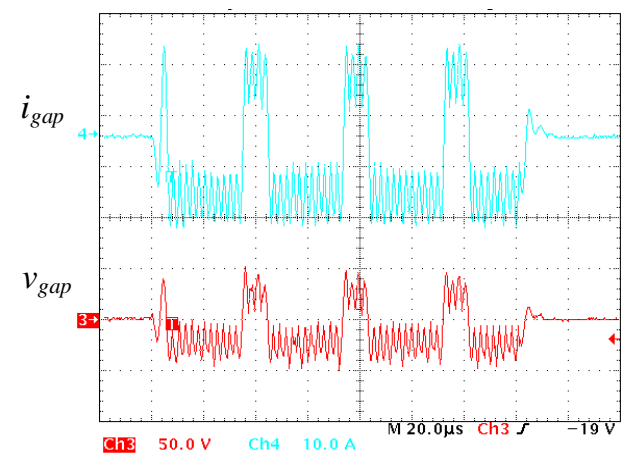

Fig. 11. Output voltage (red) and current (blue) at freqAC $=26 \mathrm{kHz}, d=25$ $\%$. Machining frequency $=3.5 \mathrm{kHz}$, duty cycle $=50 \%$. Ch4 scale: $10 \mathrm{~A} / \mathrm{div}$, Ch3 scale: $50 \mathrm{~V} /$ div, time scale: $20 \mu \mathrm{s} / \mathrm{div}$.

The proposal has also been verified in actual EDM operations. The machining operations are performed on a carbon steel workpiece with an $8 \mathrm{~mm} \varnothing$ graphite electrode. The dielectric fluid is tap water and external flushing is used. The machining frequency is $3.5 \mathrm{kHz}$ with a $50 \%$ duty cycle. Fig. 12 shows the gap voltage and current waveforms of effective discharges with different operating modes as shown theoretically in Fig. 2.

Fig. 12 (a) shows the gap voltage and current waveforms of the unipolar operating mode. Fig. 12 (b) shows the same waveforms for the bipolar mode at the machining frequency, in this case $3.5 \mathrm{kHz}, 50 \%$ duty cycle. Fig. 12 (c) shows the gap voltage and current for the bipolar mode at the inverter switching frequency, $208 \mathrm{kHz}$, and Fig. 12 (d) shows these waveforms for the bipolar mode at freqAC $=26 \mathrm{kHz}$ and $d=$ $50 \%$. In this case, Fig. 12 (d), the power measured at the input dc source was $167 \mathrm{~W}$.

Fig. 13 shows the gap voltage and current waveforms of effective discharges with the bipolar operating mode at freqAC $=26 \mathrm{kHz}$ and $d=25 \%$, Fig. 13 (a), and $d=75 \%$, Fig. 13 (b).

Table I shows the resulting cuts with the same machining conditions for the unipolar and the bipolar at freqAC = $52 \mathrm{kHz}$ and $d=50 \%$ operation modes. The operations are performed on a carbon steel workpiece with a graphite electrode, tap water as dielectric fluid and external flushing is used. The machining frequency is $4.38 \mathrm{kHz}$ with a $50 \%$ duty cycle.

Table II shows the resulting surface finish values, $R a$ (arithmetic average deviation) and $R z$ (ten-point height average), for different operating modes under the same machining conditions as those shown in Table I. The surface finish is finer in the case of the higher frequency bipolar operating mode. 


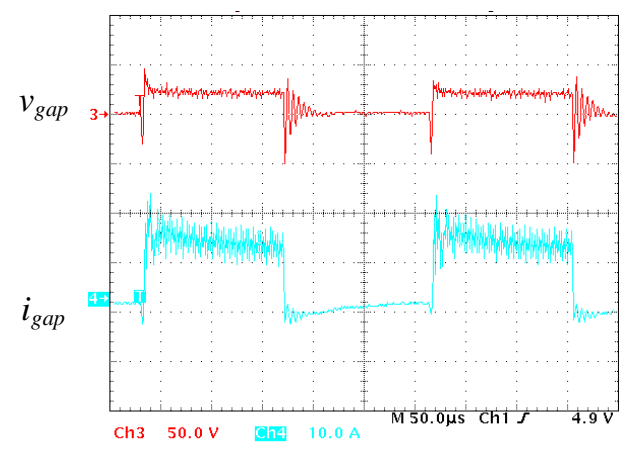

(a)

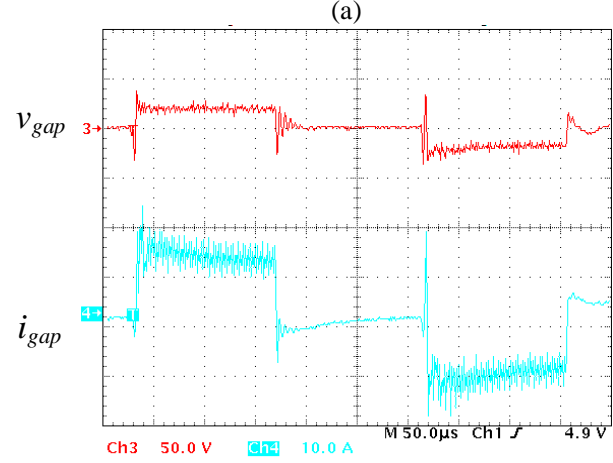

(b)

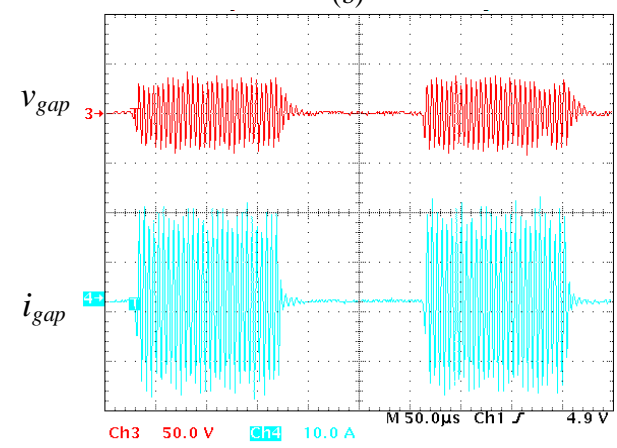

(c)

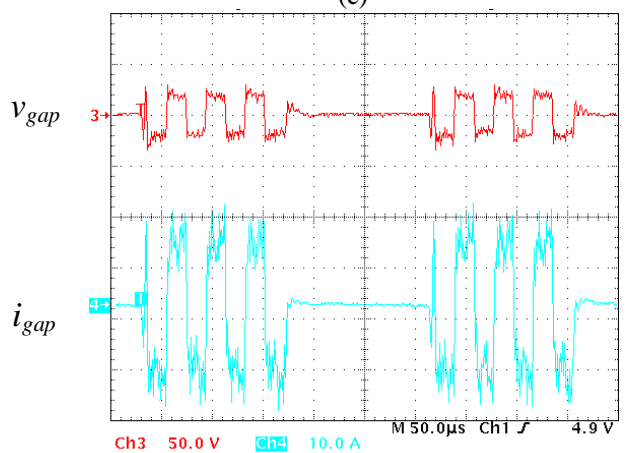

(d)

Fig. 12. Gap voltage (red) and current (blue). Machining frequency $=3.5$ $\mathrm{kHz}$, duty cycle $=50 \%$. a) Unipolar, b) bipolar at the machining frequency, c) bipolar at the switching frequency $(208 \mathrm{kHz})$ and d) bipolar at freqAC= $26 \mathrm{kHz}, d=50 \%$. Ch3 scale: $50 \mathrm{~V} / \mathrm{div}, \mathrm{Ch} 4$ scale: $10 \mathrm{~A} / \mathrm{div}$, time scale: 50 $\mu \mathrm{s} / \mathrm{div}$.

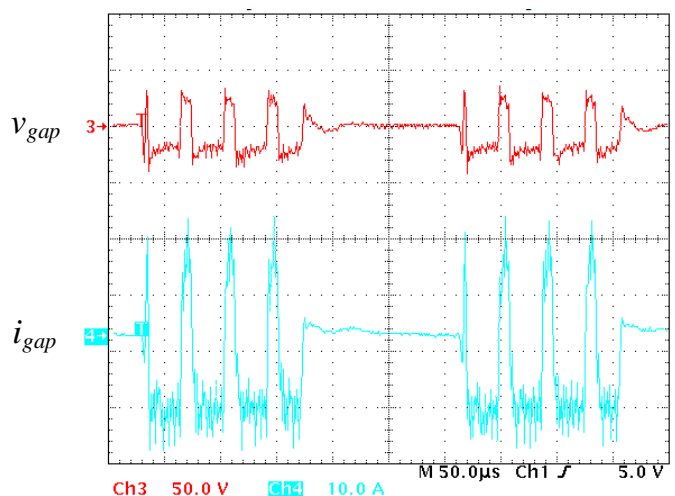

(a)

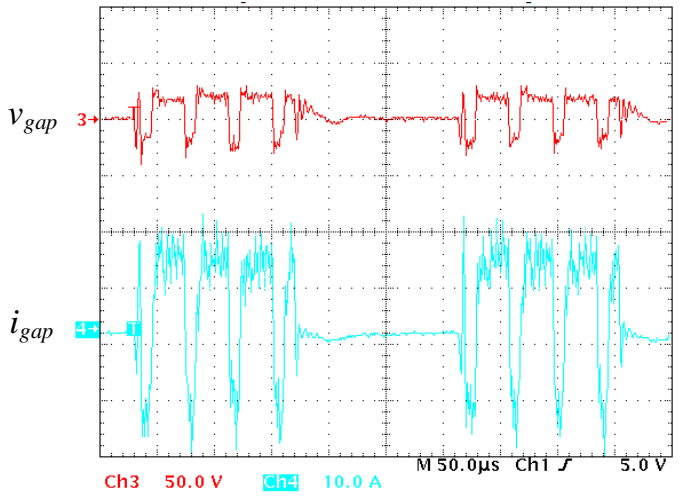

(b)

Fig. 13. Gap voltage (red) and current (blue) at freqAC $=26 \mathrm{kHz}$, a) $d=25 \%$ and b) $d=75 \%$. Machining frequency $=3.5 \mathrm{kHz}$, duty cycle $=50 \%$. Ch3 scale: $50 \mathrm{~V} / \mathrm{div}$, Ch4 scale: $10 \mathrm{~A} / \mathrm{div}$, time scale: $50 \mu \mathrm{s} / \mathrm{div}$.

TABLE I. Resulting Cuts. DifFerent Operating Modes

\begin{tabular}{|c|c|c|}
\hline $\begin{array}{l}\text { Machining } \\
\text { conditions }\end{array}$ & \multicolumn{2}{|c|}{$\begin{array}{l}\text { Machining frequency: } 4.38 \mathrm{kHz} \text {; Duty cycle }=50 \% \text {; Machining time: } 90 \mathrm{~s} \text {; } \\
\text { Dielectric fluid: tap water; Flushing: external }\end{array}$} \\
\hline Electrode & \multicolumn{2}{|c|}{ Graphite, $8 \mathrm{~mm} \varnothing$} \\
\hline Workpiece & \multicolumn{2}{|c|}{ Carbon Steel } \\
\hline $\begin{array}{l}\text { Operation } \\
\text { mode }\end{array}$ & Unipolar & $\begin{array}{c}\text { Bipolar } \\
\text { freqAC }=52 \mathrm{kHz}, d=50 \%\end{array}$ \\
\hline & ris & \\
\hline
\end{tabular}

TABLE II. Surface Finish. DifFERENT Operating Modes

\begin{tabular}{||l||c||c||}
\hline \multicolumn{1}{|c||}{ Operating mode } & $\boldsymbol{R a}(\boldsymbol{\mu m})$ & $\boldsymbol{R z}(\boldsymbol{\mu m})$ \\
\hline \hline Unipolar & 4.08 & 21.47 \\
\hline Bipolar, freqAC $=26 \mathrm{kHz}, \mathrm{d}=50 \%$ & 3.25 & 19.49 \\
\hline Bipolar, freqAC $=52 \mathrm{kHz}, \mathrm{d}=50 \%$ & 2.82 & 15.93 \\
\hline \hline
\end{tabular}




\section{CONCLUSIONS}

The back-to-back configuration of synchronous rectifiers is effective to construct four quadrant switches in rectifier stages of bipolar output current with controllable frequency and pulse width for EDM applications.

The frequency resolution and pulse width which is obtained from a high-frequency resonant inverter is enough in this application to establish a minimum loss control by adjusting the phase of the drive signals of the rectifier switches with the phase of the output current, eliminating dead times.

The proposal has been experimentally verified in steady state with the load emulated by resistances, achieving the expected behavior. Finally, machining operations have been performed to verify the different operating modes.

\section{ACKNOWLEDGMENT}

This work is sponsored by the Spanish Ministry of Science and the EU through the project CICYT-FEDERTEC2011-23612: "Power conversion with new digital control techniques and soft-saturation magnetic cores".

\section{REFERENCES}

[1] C. J. Luis, I. Puertas, G. Villa, "Material removal rate and electrode wear study on the EDM of silicon carbide," Journal of Materials Processing Technology, vol. 164-165, pp. 889-896, 2005.

[2] K. H. Ho, S.T. Newman, "State of the art electrical discharge machining (EDM)," International Journal of Machine Tools \& Manufacture, vol. 43, pp. 1287-1300, 2003.

[3] P. Fallböhmer, T. Altan ,H.-K. Tönshoff, T. Nakagawa, "Survey of die and mold manufacturing industry," Journal of Materials Process Technology, vol. 59, pp. 158-168, 1996.

[4] M. Yan, Y. Lai, "Surface quality improvement of wire-EDM using a fine-finish power supply," International Journal of Machine Tools and Manufacture, vol. 47, pp. 1686-1694, 2007.
[5] P. Bleys, J.-P. Kruth, B. Lauwers, B. Schacht, V. Balasubramanian, L. Froyen, J. Van Humbeeck, "Surface and Sub-Surface Quality of Steelafter EDM," Advanced Engineering Materials, vol. 8, pp. 15-25, 2006.

[6] M. Yan, Y. Liu, "Design, analysis and experimental study of a highfrequency power supply for finish cut of wire-EDM," International Journal of Machine Tools and Manufacture, vol. 49, pp. 793-796, 2009.

[7] A. Navarro-Crespin, V. M. Lopez, F. J. Azcondo and R. Casanueva "Four quadrant converter on AC welding application," in Proc. PCIM 2013.

[8] R. Casanueva, F.J. Azcondo, C. Brañas, "A new bipolar power supply for spark erosion based on a series-parallel resonant inverter," in Proc. IEEE APEC 2008, pp. 1904-1909.

[9] A. N. Arvindan, V. K. Sharma, "Simulation based Performance Analysis of Dual Supply Bi-directional Improved Power Quality ACDC Matrix Converter with Four Quadrant Switch Realizations," in Proc. IEEE INDICON 2005, pp. 600- 604.

[10] R. W. Erickson, D. Maksimovic, Fundamentals of Power Electronics, Springer, 2nd ed., 2001.

[11] J.W. Kolar, U. Drofenik, F.C. Zach, "VIENNA rectifier II-a novel single-stage high-frequency isolated three-phase PWM rectifier system," IEEE Trans. Ind. Electron., vol.46, pp.674-691, Aug 1999.

[12] P. Wheeler, J. Rodriguez, J. Clare, L. Empringham and A. Weinstein, "Matrix converters: technology review," IEEE Trans. Ind. Electron., vol. 49, pp. 276-288, Apr. 2002.

[13] B. J. Baliga, Power semiconductor devices. PWS Publications, 2010.

[14] K. Kobravi, R. Iravani, H.A. Kojori, "A new high switching-frequency MOSFET-based Current-Source-Converter with bidirectional powerflow capability," in Proc. IEEE APEC 2012, pp. 1179-1186.

[15] Infineon, "Improving Efficiency of Synchronous Rectification by Analysis of the MOSFET Power Loss Mechanism," Application Note, June 2009.

[16] B. Yang, J. Zhang, "Effect and Utilization of Common Source Inductance in Synchronous Rectification," in Proc. IEEE APEC 2005.

[17] A. Navarro-Crespin, V. M. Lopez, R. Casanueva, F. J. Azcondo, "Digital Control for an Arc Welding Machine Based on Resonant Converters and Synchronous Rectification," IEEE Trans. Ind. Informatics, vol. 9, pp. 839-847, May 2013. 